\title{
Influences of Age and Length of Education on rCBF-SPECT in Healthy Elderly: Diagnostic Implications for Dementia
}

\author{
Torbjörn Sundström¹, Anne Larsson², Lars Nyberg ${ }^{1}$, Katrine Riklund ${ }^{1}$ \\ ${ }^{1}$ Department of Radiation Sciences, Diagnostic Radiology, Umeå University, Umeå, Sweden; ${ }^{2}$ Department of Radiation Sciences, \\ Radiation Physics, Umeå University, Umeå, Sweden. \\ Email: torbjorn.sundstrom@diagrad.umu.se
}

Received February 25 ${ }^{\text {th }}$, 2011; revised April 11 ${ }^{\text {th }}, 2011$; accepted April $18^{\text {th }}, 2011$.

\begin{abstract}
Background: Few previous studies have described other than age- and gender related changes in regional cerebral blood flow $(r C B F)$ in healthy elderly. What is the influence of other common clinically relevant variables such as ache, education, MMSE, and smoking history? Purpose: To study rCBF in Swedish healthy elderly by single-photon emission computed tomography (SPECT) and evaluate the influence on rCBF of age, gender, education, MMSE, ache, and smoking with a focus on education in relation to the "cognitive reserve". Methods: Healthy subjects $(n=45,50-75 y)$, sampled from a large longitudinal aging study took part in an extensive examination of health and memory, including cognitive testing and socio-economic survey. After injection of 99 mTc-hexamethylpropylene amine oxime (HMPAO) followed by SPECT the rCBF-SPECT images were analyzed using statistical parametric mapping (SPM). Results: Age-related decreases in uptake were seen in interhemispheric and interlobar regions. There was a positive rCBF correlation with education in the inferior frontal lobe and a higher uptake in the left temporal lobe in an age-gender-matched high education subgroup. Conclusion: The localization of the age related findings except for the medial temporal lobe differs markedly from typical dementia related findings. A reduction close to interhemispheric or interlobar space should always be related to chronological age. Education seems to have an influence on basal brain function at a resting-state condition. Knowledge of normal rCBF variations for variables such as age and education should be considered when making clinical diagnosis. The findings could be interpreted as further support for the theory of cognitive reserve.
\end{abstract}

Keywords: Normal Material, Dementia, Alzheimer's Disease, 99 mTc-HMPAO rCBF-SPECT, Brain Imaging, Neuropsychology, Regional Cerebral Blood Flow, Cognitive Reserve

\section{Introduction}

The last two decades have shown great advances in functional brain imaging. The instrumentation and processing software along with implementation of standardization techniques have opened a new era of brain research. In all functional brain imaging studies there is a need of reliable control groups [1] and the knowledge of the normal variation of regional cerebral blood flow (rCBF) at rest is important when interpreting the results in brain imaging studies. In the clinical situation where single photon emission computed tomography (SPECT) scans of the brain usually are analyzed only by visual assessment, the first judgment is always whether the presented $\mathrm{rCBF}$ is normal. Therefore, the knowledge of the normal va- riation of rCBF covariates is crucial. The most common reason for referral to an rCBF-SPECT investigation is aid for diagnosis of dementia and notably Alzheimer's disease (AD) [2-4]. The prevalence of $\mathrm{AD}$ in our aging society is rapidly growing [5] and early diagnosis followed by pharmacological treatment is important [6]. Variables such as age and gender are of course always known in the clinical setting. Other variables such as education length, Mini-Mental State Examination (MMSE), history of ache and smoking can easily be provided and the effect of these variables on the "normal" rCBF is of great interest.

The effect of age and gender has been in focus lately and the normal rCBF has been evaluated in several previous studies [7-10]. Age has a considerable effect on 
function [7,8] and structure of the brain [9]. Especially the grey matter is affected and the amount of grey matter seems to decrease linearly with age $[7,10]$. In contrast, the white matter is reported to be intact or even increase $[7,10]$ until the mid-50 s, after which it declines with an accelerated rate [10]. There are evidence suggesting that the brain in aging and $\mathrm{AD}$ actively adapts to a progressive fuel deprivation characterized by hypo-metabolism and oxidative stress which finally result in neuronal loss [11]. Earlier 133Xe studies [12,13] and voxel based MRI studies [14] indicate that the global loss of both function and structure is about $0.3 \%-0.5 \%$ per year after the age of 20.

The estimation of rCBF with 99 mTc hexamethylpropylene amine oxime (HMPAO) and SPECT is a semiquantitative method [15]. An intensity normalization of the measured tracer uptake is necessary. The images are usually scaled to an internal reference, e.g., the whole brain or a cerebellar mean. Regions that age more slowly than the reference region appear to have increased perfusion, i.e. preservation [12], while regions that age faster appear to have decreased perfusion. Regional preservation has been reported bilaterally in the occipital-cuneus area [16], thalamus and putamen [8], sensorimotor and parietal regions [17]. In a large voxel based study of 465 subjects, age-related preservation in white matter was detected with structural MRI [14]. This was suggested to be an effect of two opposing factors, the age related loss of myelin [18] and an age related expansion of the capillary network and extra cellular space [19]. Another suggested theory is that age-related preservation in white matter arises from age related changes in brain anatomy, due to a partial-volume effect (PVE) in regions where the shrinking white matter becomes thinner than the resolution of the detector system. The detected rCBF will then be influenced by surrounding grey matter which has a higher rCBF [20]. Losses with age, measured with SPECT and positron emission tomography (PET), have been consistently reported in the frontal lobe, in particular the anterior cingulate, but also in the insula and superior temporal and parietal lobes [20].

Gender differences in brain function and structure have previously been reported, and the most consistent results are neuropsychological tests showing that women perform better than men on tests of both verbal fluency and episodic memory with an inverse relationship on visuospatial tasks [21]. It is also known that there are differences in the size of the brain [22]. When looking at results of previous rest and activation studies of rCBF and regional cerebral metabolic rate for glucose (rCMRglc) with PET, SPECT and fMRI, the results are more complex and the findings can be controversial. For instance a higher uptake is reported in women at rest in the mid- cingulate/corpus callosum [23], temporal [23], parietal regions [16,23] and hypothalamus [24]. A lower rCBF is reported in the cerebellum [16], left anterior temporal [16], orbitofrontal cortex [16], right insula, middle temporal gyrus, and medial frontal lobe [24]. On the other hand there are also recent studies reporting no gender based differences [20].

Education length seems to have a strong influence on brain function and since it can postpone the clinical manifestation of $\mathrm{AD}[25,26]$, education length should presumably also have influence on the normal rCBF. The potential neuro protective effect of education and the delay of clinical manifestations of $\mathrm{AD}$ have gained much interest $[27,28]$. The cognitive reserve (CR) or the ability to cope with advancing brain pathology without showing symptoms [29] is suggested to be mediated through education or IQ [30]. A recent study showed an increased rCBF in left temporal regions in AD patients with a high compared to low length of education $(10+/-4$ year vs. 1+/-1 year) [31]. "The Cognitive Ability Screening Instrument” (CASI) [32] that was used for grading the AD severity in that study showed a significantly higher cognitive level in the high education group $(67.7+/-11.4$ vs $44.0+/-11.5)$. The connection of education length, the rCBF in the temporal lobe and the location of the semantic memory [33] is interesting since the temporal lobe often is affected in AD. In another recent article the CR in AD was evaluated and years of formal schooling had a negative association with cerebral perfusion and positive association with cognitive test scores [34]. The CR is suggested to be an effect of education with an increased capacity to use alternative brain circuits instead of locally increased synaptic connections [34].

The acute effect of smoking on rCBF has been evaluated in several SPECT and PET studies [35-39] while only a few studies relate to the chronic effect on rCBF. Acute effects are reported as increases in rCBF in the occipital cortex, cerebellum and thalamus, and decreases in the anterior cingulate, nucleus accumbens and amygdala. In a study of previous smokers a decrease in rCBF was still seen six years after quit smoking but was reversed after additional 3 years [40].

Chronic pain in the elderly and middle-aged population is a common problem [41] although the effect on the normal rCBF has not been studied before. In a recent study by Sundström et al. [42] a non-traumatic chronic neck pain patient group demonstrated a low rCBF in temporal regions although this was not seen in a traumatic chronic neck pain patient group. In this study both groups show tendency of an increased rCBF in somatosensory regions.

In summary, previous findings suggest that several variables may affect rCBF but the nature of such influ- 
ences remain to be conclusively determined. The aim of the present study was therefore to further evaluate the effect on the rCBF of common variables, such as age, gender, education, history of smoking and ache by using rCBF-SPECT with HMPAO at rest. A special focus was on education and findings that could be related to the notion of cognitive reserve.

\section{Material and Methods}

The study was approved by both the Ethics and the Radiation Protection Committee of Umeå University. Written informed consent was obtained according to the Declaration of Human Rights of Helsinki 1975.

\subsection{Subjects}

Forty-nine healthy subjects (26 men, 23 women) in ages from 50 to 75 were consecutively included from a large prospective research project in the community of Umeå, i.e. the Betula project [43]. The cohorts are recruited with a 5 year age interval. The purpose of the ongoing Betula project is to explore the development of memory functions in adulthood, determine risk factors for dementia, and to determine early preclinical signs of dementia. All subjects in the Betula project take part in an extensive examination of health and memory every fifth year, including cognitive testing and interviews regarding critical life events and socio-economic issues. In addition, smoking habits (start and stop date) and ache (back, joints, shoulders and/or arms/legs: one unit each) are recorded. The inclusion criterion in Betula is a good subjective and objective health. All subjects have a good mental and physical health based on self assessment, normal lab tests and a normal health examination without a history of psychiatric disorder, stroke or dementia. The exclusion criteria in this study was a history of physical or mental illness or chronic drug treatment, alcohol or drug abuse, previous brain trauma, cerebrovascular disorder, hypertension, diabetes, epilepsy, psychiatric disorders, allergy, other systemic disease, malignancy, endocrine disorders, renal dysfunction, gynaecological disorders, infections or metabolic diseases or a MMSE below 25.

All subjects underwent a neuropsychological assessment by an experienced neuropsychologist. The cognitive and functional level was estimated, including MMSE [44]. Each healthy subject was extensively examined and interviewed about health status, activities of daily living (ADL) by a nurse. Socioeconomic factors and critical life events were estimated by questionnaires including selfreported number of years of formal education [43,45]. All tests are extensively described in Nilsson et al. (1997) [43].
Two subjects were excluded due to a MMSE below 25 and two subjects were excluded due to an incomplete rCBF SPECT scan (> 50\% of the cerebellum was not covered).

Forty-five subjects were evaluated (25 men, 20 women, age 50 - 75). The characteristics of the included healthy subjects regarding gender, age, education, MMSE, smoking history and reported ache are described in Table $\mathbf{1 .}$ To compare the influence of each variable on $\mathrm{rCBF}$, the subjects were grouped based on the evaluated variable, as summarized in Table $\mathbf{1}$.

\subsection{Image Acquisition and Processing}

All rCBF-SPECT studies were performed on a threeheaded gamma camera, Neurocam (General Electric, Milwaukee, WI, US) equipped with low energy high resolution (LEHR) collimators at the department of Nuclear Medicine, Diagnostic Radiology, Norrland's University Hospital. The SPECT studies were performed in a $360^{\circ}$ stepwise rotation, with 90 seconds acquisition time in 64 equally spaced angles. The image matrices were $128 \times 128$ pixels and the spatial resolution of the system (FWHM) at a $100 \mathrm{~mm}$ distance from the camera is $6.9 \mathrm{~mm}$. The transmission dependent convolution subtraction method with one iteration [46,47], was used for scatter correction before reconstruction. The images were prefiltered with a 2D Hanning filter with a cut-off frequency of $1.0 \mathrm{~cm}^{-1}$ and reconstructed into transaxial slices with the iterative orderedsubsets ML-EM (OSEM) [48] algorithm using 8 iterations and a subset of 4 images. A homogeneous attenuation correction was used where the outline of the homogeneous attenuation map was defined from a preceding step with an iterative reconstruction without attenuation correction. The map was constructed of voxels with a value above zero after dilation and erosion processes, to a match the contour of the skull. The attenuation coefficient was set to the value of water for $140 \mathrm{keV}$ photons, $0.154 \mathrm{~cm}^{-1}$. The pixel size is $2.0 \times 2.0 \mathrm{~mm}$ in the reconstructed images. The reconstructed image data was exported in Interfile format and converted to ANALYZE format before further analysis.

On the day of examination the radiopharmaceutical ${ }^{99 \mathrm{~m}} \mathrm{Tc}-\mathrm{HMPAO}$ was prepared by eluting ${ }^{99 \mathrm{~m}} \mathrm{TcO}_{4-}$ from a ${ }^{99} \mathrm{Mo} /{ }^{99 m} \mathrm{Tc}$ generator just before adding it to a freezedried kit (Ceretec ${ }^{\mathrm{TM}}$, Nycomed Amersham plc, Buckinghampshire, UK) according to the instructions of the manufacturer. All healthy controls received an activity of $675 \mathrm{MBq}$, according to ethical guidelines. The radiotracer was administered after 30 minutes rest with eyes closed in a dim-lighted room. Following injection, a 10 to 40 minute rest was undertaken, before examination 
Table 1. Characteristics of included healthy controls subjects. Gender, age, education, MMSE, smoking history and reported ache are described for each grouping variable. The figures are presented as: mean (mean men; mean women) range.

\begin{tabular}{|c|c|c|c|c|c|c|}
\hline $\begin{array}{l}\text { Grouping } \\
\text { variable }\end{array}$ & $\begin{array}{c}\text { Number } \\
\text { (Men: Female) }\end{array}$ & Mean age (years) & Education (years) & MMSE $(0$ - 30) & Smoke (years) & Reported ache \\
\hline Men & 25 & $62.850-75$ & $10.56-20$ & $28.226-30$ & $10.50-40$ & $0.80-3$ \\
\hline Women & 20 & $63.750-75$ & $10.16-19$ & $2825-30$ & $5.40-39$ & $1.10-3$ \\
\hline $\begin{array}{l}\text { Age } \\
20-60(y)\end{array}$ & $20(11 ; 9)$ & $\begin{array}{c}55.7 * * *(55.5 ; 55.8) \\
50-62\end{array}$ & $\begin{array}{c}12.6 * * *(13 ; 12.1) \\
7-20\end{array}$ & $\begin{array}{c}28.2(28.5 ; 27.8) \\
25-30\end{array}$ & $\begin{array}{c}8.8(13.1 ; 3.4) \\
0-35\end{array}$ & $\begin{array}{c}1.4 *(1.3 ; 1.4) \\
0-3\end{array}$ \\
\hline $\begin{array}{l}\text { Age } \\
64-75(y)\end{array}$ & $25(14 ; 11)$ & $\begin{array}{c}69.2 * * *(68.5 ; 70.1) \\
64-75\end{array}$ & $\begin{array}{c}8.5 * * *(8.6 ; 8.5) \\
6-16\end{array}$ & $\begin{array}{c}28(27.9 ; 28.1) \\
25-30\end{array}$ & $\begin{array}{c}7.8(8.4 ; 6.9) \\
0-40\end{array}$ & $\begin{array}{c}0.6 *(0.4 ; 0.8) \\
0-3\end{array}$ \\
\hline $\begin{array}{l}\text { High } \\
\text { education }\end{array}$ & $24(14 ; 10)$ & $\begin{array}{c}59.8 * *(60.3 ; 59.1) \\
50-75\end{array}$ & $\begin{array}{c}13.1 * * *(13.2 ; 13.1) \\
9.5-20\end{array}$ & $\begin{array}{l}28.3(28.3 ; 28.4) \\
26-30\end{array}$ & $\begin{array}{l}8.5(12.3 ; 3.3) \\
0-40\end{array}$ & $\begin{array}{c}0.9(0.9 ; 1) \\
0-3\end{array}$ \\
\hline Low education & $21(11 ; 10)$ & $\begin{array}{c}67 * *(66 ; 68.2) \\
\quad 52-75\end{array}$ & $\begin{array}{c}7.1^{* * *}(7.2 ; 7.1) \\
6-9\end{array}$ & $\begin{array}{c}27.8(28.1 ; 27.5) \\
25-30\end{array}$ & $\begin{array}{c}7.8(8.2 ; 7.4) \\
0-39\end{array}$ & $\begin{array}{c}1(0.7 ; 1.2) \\
0-3\end{array}$ \\
\hline MMSE $<29$ & $23(13 ; 10)$ & $\begin{array}{l}62.6(62.8 ; 62.4) \\
50-75\end{array}$ & $\begin{array}{c}10(10.48 ; 9.4) \\
6-20\end{array}$ & $\begin{array}{c}27^{* * *}(27.4 ; 26.6) \\
25-28\end{array}$ & $\begin{array}{c}10.7(12.2 ; 8.7) \\
0-40\end{array}$ & $\begin{array}{c}1.1(1 ; 1.3) \\
0-3\end{array}$ \\
\hline $\begin{array}{l}\text { MMSE } 29 \quad- \\
30\end{array}$ & $22(12 ; 10)$ & $\begin{array}{c}63.8(62.8 ; 64.9) \\
50-75\end{array}$ & $\begin{array}{c}10.7(10.7 ; 10.8) \\
6-19\end{array}$ & $\begin{array}{c}29.2 * * *(29.1 ; \\
29.3) \\
29-30\end{array}$ & $\begin{array}{l}5.6(8.6 ; 2) \\
\quad 0-35\end{array}$ & $\begin{array}{c}0.7(0.6 ; 0.9) \\
0-3\end{array}$ \\
\hline $\begin{array}{l}\text { History of } \\
\text { smoking }\end{array}$ & $16(11 ; 5)$ & $\begin{array}{l}62.5(62.2 ; 63.2) \\
50-75\end{array}$ & $\begin{array}{c}10.1(10.8 ; 8.5) \\
7-20\end{array}$ & $\begin{array}{c}27.9(28.2 ; 27.2) \\
25-30\end{array}$ & $\begin{array}{c}23.1^{* * *} \\
(23.8 ; 21.4) \\
6-40\end{array}$ & $\begin{array}{c}1.2(1.1 ; 1.4) \\
0-3\end{array}$ \\
\hline $\begin{array}{l}\text { No history of } \\
\text { smoking }\end{array}$ & $29(14 ; 15)$ & $\begin{array}{c}63.6(63.3 ; 63.8) \\
50-75\end{array}$ & $\begin{array}{c}10.5(10.3 ; 10.6) \\
6-19\end{array}$ & $\begin{array}{c}28.2(28.2 ; 28.2) \\
25-30\end{array}$ & $0^{* * *}$ & $\begin{array}{l}0.8(0.6 ; 1) \\
0-3\end{array}$ \\
\hline Ache & $26(13 ; 13)$ & $\begin{array}{c}61.8(61 ; 62.7) \\
50-75\end{array}$ & $\begin{array}{c}10.4(10.6 ; 10.1) \\
6-19\end{array}$ & $\begin{array}{c}28.1(28.2 ; 27.9) \\
25-30\end{array}$ & $\begin{array}{c}11.3(15.9 ; 6.7) \\
0-40\end{array}$ & $\begin{array}{c}1.6^{* * * *} \\
(1.5 ; 1.7) \\
1-3\end{array}$ \\
\hline No-ache & $19(12 ; 7)$ & $\begin{array}{c}65(64.8 ; 65.4) \\
50-75\end{array}$ & $\begin{array}{l}10.3(10.5 ; 10) \\
\quad 6-20\end{array}$ & $\begin{array}{c}28.1(28.2 ; 28) \\
25-29\end{array}$ & $\begin{array}{c}3.9(4.6 ; 2.9) \\
0-34\end{array}$ & $\begin{array}{c}0^{* * *} \\
\left(0^{* * *} ; 0^{* * *}\right) \\
0-0\end{array}$ \\
\hline \multicolumn{7}{|l|}{$\begin{array}{l}\text { Age gender } \\
\text { matched } \\
\text { pairs }\end{array}$} \\
\hline $\begin{array}{l}\text { High } \\
\text { education }\end{array}$ & $11(6 ; 5)$ & $\begin{array}{c}64.5(63.3 ; 65.8) \\
50-75\end{array}$ & $\begin{array}{c}13.2 * * *(13.7 ; 12.6) \\
10-20\end{array}$ & $\begin{array}{c}28.6(28.2 ; 29.2) \\
27-30\end{array}$ & $\begin{array}{c}13.1(21.2 ; 3.4) \\
0-40\end{array}$ & $\begin{array}{l}0.7(0.5 ; 1) \\
0-2\end{array}$ \\
\hline Low education & $11(6 ; 5)$ & $\begin{array}{c}64.8(63.8 ; 66) \\
52-75\end{array}$ & $\begin{array}{c}7.4 * * *(7.3 ; 7.5) \\
6-9\end{array}$ & $\begin{array}{c}27.5(28 ; 27) \\
25-30\end{array}$ & $\begin{array}{l}6.8(10 ; 3) \\
\quad 0-35\end{array}$ & $\begin{array}{c}1.3(1.2 ; 1.4) \\
0-3\end{array}$ \\
\hline Ache & $14(8 ; 6)$ & $\begin{array}{c}64.1(63.9 ; 64.3) \\
50-75\end{array}$ & $\begin{array}{l}9.1(9.1 ; 9) \\
\quad 6-19\end{array}$ & $\begin{array}{c}27.6(27.9 ; 27.2) \\
25-29\end{array}$ & $\begin{array}{c}11.5^{*}(13.4 ; 9) \\
0-40\end{array}$ & $\begin{array}{c}1.8^{* * *} \\
(1.5 ; 2.2) \\
1-3\end{array}$ \\
\hline No-ache & $14(8 ; 6)$ & $\begin{array}{l}64.1(64.4 ; 63.8) \\
\quad 50-75\end{array}$ & $\begin{array}{c}9.7(8.9 ; 10.7) \\
6-17\end{array}$ & $\begin{array}{c}28(28.1 ; 27.8) \\
25-29\end{array}$ & $\begin{array}{c}2.5^{*}(1.9 ; 3.3) \\
0-20\end{array}$ & $\begin{array}{c}0^{* * *} \\
\left(0^{* * *} ; 0^{* * *}\right) \\
0-0\end{array}$ \\
\hline
\end{tabular}

$* p<0.05 ; * * p<0.01 ; * * * p<0.001$.

with the scintillation camera [49]. In order to obtain a robust scanning geometry in the gamma camera, the head was positioned in a carbon fibre holder connected to the bed and fixed using an individually formed thermoplastic face mask.
Statistical parametric mapping (SPM), version 2 (Welcome Department of Cognitive Neurology, University College, London) was used to study differences in rCBF between the groups. Calculations were performed in Matlab 6.5.1 (Mathworks Inv., Sherborn, Mass., US). Before 
the statistical analysis, the rCBF-SPECT data were normalized to the MNI SPECT template (SPM2) and smoothed with a 12 mm FWHM 3D Gaussian filter kernel [47]. The confounding effect of varying global activity was removed by proportional scaling to a global value of $50 \mathrm{ml} / \mathrm{min}$ per $100 \mathrm{~g}$ and a standard level of grey matter threshold of 0.8 was used to exclude voxels of minor interest in the analysis.

\subsection{Statistical Evaluation}

Two different SPM-models based on t-statistics of the general linear model (GLM) analysis were used to detect relations between the investigated variables and $\mathrm{rCBF}$. In a first analysis the subjects were divided into groups regarding each variable and analyzed with "compare-populations". To further examine positive and negative correlations for variables with a detected influence on rCBF in the first "compare-populations" analysis, a second correlation analysis was made with the SPM model, "Singlesubject, covariates only”. The statistical level for significant results was set to $p<0.05$ corrected for false discovery rate (FDR) [50] on voxel level and $p<0.05$ corrected for multiple non-independent comparisons on cluster level. The extent threshold was 10 voxels $(k=10)$. To determine the anatomical localization of the SPM data the Montreal Neurological Institute coordinates (MNI) were converted to the Talairach brain atlas using a nonlinear function as described at the CBU Imaging web site (http://www.mrc-cbu.cam.ac.uk/Imaging/mnispace.html). The SPM add on MNI Space utility (MSU) and Talairach Space utility (TSU) developed in the PET Lab of Institute of the Human Brain

(http://www.ihb.spb.ru/ pet_lab/MSU/MSUMain.html) was used to analyze the anatomical extension of the clusters in terms of anatomical region labels used by the Talairach Daemon (http://www.talairach.org/daemon. html). Cluster extension is described in terms of hemispheres, brain lobes, gyri-sulci, white and grey matter as well as Brodmann areas. In order to visualize the anatomical localizations the SPM data were visualized by the Talairach Space utility (http://www.ihb.spb.ru/ pet_lab/TSU/TSUMain.html) and by superimposing data on MRI-templates in SPM.

In the AnCova SPM analysis, the influence on the rCBF of the variables age, gender, education, MMSE and ache were evaluated by dividing the sample into subgroups. The sample was divided into two age groups with a matching range and size: 50 - 60 and 64 - 75 years of age, the cut-off also matches the time of retirement in Sweden. In order to evaluate the influence of education, the cut-off length of formal schooling was set to nine years, which is the length of compulsory school of edu- cation in Sweden. The resulting groups with high education (HE) or low education (LE) were of matching size. To evaluate the variable of MMSE the cut off value was set to 28 for a lower MMSE. The reason for this was that the chosen level of MMSE for inclusion in previous rCBF-SPECT studies of healthy subject has been set to 29 - 30 [7,8]. The influence of smoking was evaluated by comparing subjects with a history of smoking to neversmokers. Subjects reporting ache were compared with subjects without reported ache.

\section{Results}

\subsection{Characteristics of the Subgroups of the Healthy Controls}

The older age group has a mean age of 69.2 (range 64 $75)$ and the younger 55.7 years of age (range 50 - 62). There was a significant difference in length of education $(p<0.001)$ and reported ache $(p<0.05)$ between these subgroups, with a mean educational length of 12.6 years in the younger and 8.5 in the older group. On average the younger subgroup reported ache from 0.4 locations compared to the older group that reported 0.6 locations.

In the evaluation of subgroups based on educational length, the mean educational length in HE is 13.1 and 7.1 years in the LE group respectively. There was also a significant difference $(p<0.01)$ of age between HE and LE with a mean age of 59.8 in HE and 67 years in LE.

For the other grouping variables, MMSE, smoking and ache, only the selected variable is significantly different. In the age and gender matched pairs regarding the variable of ache there were also a significant difference ( $p<$ 0.05 ) in smoking history.

\section{2. rCBF Variation Related to Age and Gender}

Significant differences in rCBF were detected between the two age groups of 50 - 60 years and 64 - 75 years. The older group had four extensive regions with a decreased uptake in both hemispheres (Table 2). All regions are located in close relation to interhemispheric or interlobar space. The largest cluster extends from a region including the Sylvian fissure towards the midline passing the cisterna vallecula cerebri and continues to bilateral parts of lamina terminalis. A second region is broadly symmetric around the midline and includes the gyrus cinguli and interhemispheric space between the limbic and frontal lobes. A third region involves a dorsal part of Sylvian fissure on the left side extending through the temporal lobe to the brain surface, and finally the fourth region includes frontal parts of the Sylvian fissure on the left side. Figure 1 shows the statistical parametric map of the uptake differences between the age-groups. 
Table 2. SPM data of rCBF differences in age-groups and educational length-groups (matched for age and gender). The table shows size and Talairach coordinates of anatomical locations of significant clusters and peaks. The regions presented are significant at corrected $p$-value of $p<0.05$ in clusters and/or $p<0.05$ (FDR) in peaks.

\begin{tabular}{|c|c|c|c|c|c|c|c|c|}
\hline & $\begin{array}{l}\text { Size } \% \text { of } \\
\text { cluster* }\end{array}$ & $\begin{array}{l}\text { Size } \\
\mathrm{ml}\end{array}$ & $\begin{array}{l}\text { Corrected } p \\
\text { value, whole } \\
\text { cluster }\end{array}$ & $\begin{array}{l}\text { Number } \\
\text { of voxels } \\
\text { in cluster }\end{array}$ & $\begin{array}{l}\text { Fdr-corrected } p \\
\text { value of voxel }\end{array}$ & $\begin{array}{l}T \text { value of } \\
\text { voxel }\end{array}$ & $\begin{array}{l}\text { Uncorr. } p \\
\text { value of } \\
\text { voxel }\end{array}$ & $\begin{array}{c}\text { Talairach } \\
\text { coordinates } \\
\mathrm{x}, \mathrm{y}, \mathrm{z}\end{array}$ \\
\hline \multicolumn{9}{|l|}{ Anatomical region } \\
\hline \multicolumn{9}{|l|}{ AGE Young $>$ Old } \\
\hline \multicolumn{9}{|l|}{ Cluster 1} \\
\hline $\begin{array}{l}\text { R. Frontal Lobe, Inferior } \\
\text { Frontal Gyrus }\end{array}$ & 26 & 3.5 & 0.000 & 1668 & 0.015 & 5.22 & 0.000 & $34,15,18$ \\
\hline Unidentified & 40 & 5.3 & & & 0.015 & 4.88 & 0.000 & $26,16,24$ \\
\hline L. Frontal Lobe & 5 & 0.7 & & & & & & \\
\hline \multicolumn{9}{|l|}{ R. Temporal Lobe } \\
\hline \multicolumn{9}{|l|}{ Cluster 2} \\
\hline $\begin{array}{l}\text { Inter-Hemispheric, } \\
\text { Unidentified }\end{array}$ & 29 & 4.8 & 0.000 & 2058 & 0.015 & 5.16 & 0.000 & $2,62,4$ \\
\hline $\begin{array}{l}\text { R. Limbic Lobe, } \\
\text { Anterior Cingulate }\end{array}$ & 13 & 2.1 & & & 0.015 & 4.9 & 0.000 & 4, 32, 22 \\
\hline $\begin{array}{l}\text { L. Frontal Lobe, Medial } \\
\text { Frontal Gyrus }\end{array}$ & 37 & 6.2 & & & 0.015 & 4.82 & 0.000 & $-6,64,0$ \\
\hline R. Frontal Lobe & 8 & 1.4 & & & & & & \\
\hline L. Limbic Lobe & 10 & 1.6 & & & & & & \\
\hline \multicolumn{9}{|l|}{ Cluster 3} \\
\hline L. Temporal Lobe & 51 & 2.5 & 0.020 & 608 & 0.017 & 4.41 & 0.000 & $-28,18,-26$ \\
\hline $\begin{array}{l}\text { L. Frontal Lobe, Inferior } \\
\text { Frontal Gyrus }\end{array}$ & 16 & 0.8 & & & 0.021 & 4.06 & 0.000 & $-57,25,-8$ \\
\hline Unidentified & 33 & 1.6 & & & & & & \\
\hline \multicolumn{9}{|l|}{ Cluster 4} \\
\hline $\begin{array}{l}\text { L. Temporal Lobe, Mid- } \\
\text { dle Temporal Gyrus }\end{array}$ & 64 & 5.1 & 0.002 & 1009 & 0.017 & 4.39 & 0.000 & $-63,-16,-13$ \\
\hline $\begin{array}{l}\text { L. Frontal Lobe, } \\
\text { Precentral Gyrus }\end{array}$ & 4 & 0.4 & & & 0.017 & 4.38 & 0.000 & $-46,-11,6$ \\
\hline Unidentified & 20 & 1.6 & & & & & & \\
\hline \multicolumn{9}{|l|}{ Cluster 5} \\
\hline $\begin{array}{l}\text { L. Temporal Lobe, } \\
\text { Superior Temporal } \\
\text { Gyrus }\end{array}$ & 100 & 0.9 & 0.617 & 110 & 0.021 & 4.06 & 0.000 & $-57,-44,11$ \\
\hline \multicolumn{9}{|l|}{ Cluster 6} \\
\hline $\begin{array}{l}\text { L. Sub-lobar, } \\
\text { Extra-Nuclear }\end{array}$ & 98 & 0.4 & 0.882 & 46 & 0.029 & 3.67 & 0.000 & $-26,-31,11$ \\
\hline \multicolumn{9}{|l|}{ Cluster 7} \\
\hline Unidentified & 94 & 0.1 & 0.969 & 17 & 0.032 & 3.56 & 0.000 & $-65,14,12$ \\
\hline L. Frontal Lobe & 6 & 0.0 & & & 0.039 & 3.4 & 0.001 & $-63,20,6$ \\
\hline \multicolumn{9}{|l|}{ Education matched HE $>$ LE } \\
\hline \multicolumn{9}{|l|}{ Cluster 1} \\
\hline $\begin{array}{l}\text { L. Temporal Lobe, } \\
\text { Fusiform Gyrus }\end{array}$ & 75 & 0.7 & 0.015 & 118 & 0.048 & 7.09 & 0.000 & $-48,-40,-20$ \\
\hline $\begin{array}{l}\text { Anterior Cerebellar } \\
\text { Lobe }\end{array}$ & 8 & 0.07 & & & & & & \\
\hline \multicolumn{9}{|l|}{ Cluster 2} \\
\hline $\begin{array}{l}\text { Inter-Hemispheric, } \\
\text { Unidentified }\end{array}$ & 55 & 0.24 & 0.088 & 55 & 0.048 & 6.25 & 0.000 & $0,54,-11$ \\
\hline L. Frontal Lobe & 36 & 0.016 & & & & & & \\
\hline R. Frontal Lobe & 9 & 0.04 & & & & & & \\
\hline \multicolumn{9}{|l|}{ Cluster 3} \\
\hline $\begin{array}{l}\text { L. Temporal Lobe, Su- } \\
\text { perior Temporal } \\
\text { Gyrus }\end{array}$ & 41 & 0.62 & 0.003 & 187 & 0.048 & 5.79 & 0.000 & $-67,-21,8$ \\
\hline Unidentified & 59 & 0.88 & 0.000 & & 0.048 & 5.54 & 0.000 & $-69,-19,1$ \\
\hline
\end{tabular}

* MSU (MNI Space utility) was used for an anatomical description of the significant clusters in terms of the Talairach daemon atlas "brain lobe” level. This is expressed as per cent of cluster. 


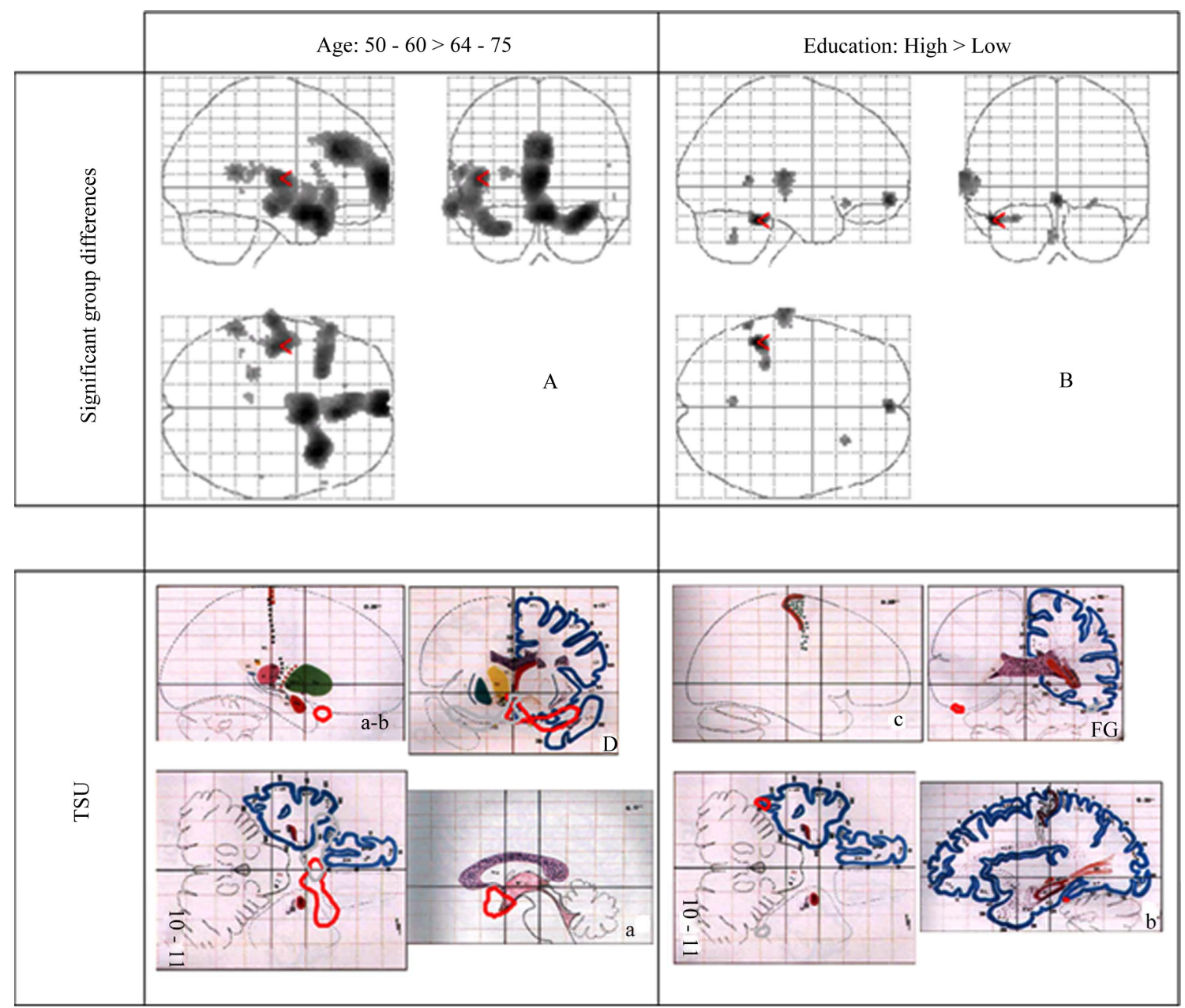

Figure 1. The first row shows significant SPM results in form of Maximum intensity projections (MIP) of the T statistics $(p<$ 0.05 FDR corrected). There are an increased uptake in the younger subgroup (A: 50 - $60>64-75)$ and in the subgroup with a longer education (B: High Education > Low education). In the second row parts of the significant uptake of each comparison is illustrated in 2-dimensional transaxial sagital and coronal planes using the SPM add-on TSU (Talairach Space utility).

No regions with a significantly lower uptake were detected in the younger group compared to the older group. No significant differences were seen at the comparison between men and women.

\section{3. rCBF Variation Related to Education}

No significant rCBF differences were seen between the groups with high versus low length of education, but when the subjects were matched regarding age and gender into 11 pairs there was a significantly higher uptake in the left temporal lobe in the HE group, Figure 1, Table 2.

\section{4. rCBF Variation Related to MMSE, Smoking and Ache}

No significant differences were seen in the comparison between subjects with high and low MMSE performance, smokers vs non-smokers, or groups with or without ache.

\subsection{Positive and Negative Correlation with rCBF for Age and Education}

There were three significant extensive clusters with a negative rCBF correlation with age. All three regions were partly overlapping with the result from the group analysis, and localized in the left temporal and bilateral frontal regions including interhemispheric and interlobar regions, Figure 2, Table 3. The SPM correlation analysis also showed a significant cluster with positive rCBF correlation with age in the right visual cortex with a mirrored non-significant cluster on the opposite side. The length of education, correlated to the rCBF activity in a cluster in the inferior frontal gyrus ( $p=0.05$ corrected in cluster). This regional effect was not observed in the group comparison.

\section{Discussion}

The present study of the influence on rCBF of easily- 
provided variables in the clinical setting such as age, gender, education length, smoke and ache in the clinical setting among healthy elderly shows that age is the dominating contributor to the variation of tracer uptake in rCBF-SPECT. Among the other analyzed variables only education length had a significant influence on rCBF. Gender, MMSE, reported ache and smoking history did not show any influence on rCBF in this study.

\subsection{Age Related Differences}

There is an age related variation of uptake in both the group and correlation analysis. There were extensive regions with a lower rCBF in the older group. The regions are partially centred close to sulci, cisterns or interhemispheric space, and there was an overlap in both the group and correlation analysis. Similar findings have previously been reported [16,20,51] although these studies have a younger age range of included subjects and several of them did not include subjects over 65 years of age. The pattern of a low uptake in interlobar interhemispheric space was more pronounced at a lower threshold of significance, not presented here, where the uptake differences also showed a more symmetric distribution. There is also an age-related reduction of uptake in anterior cingulum which is consistent with other studies [16,20,52].

The rCBF reductions in these anatomical regions are an effect of a rCBF reduction in combination with atrophy related to age. The correlation between $\mathrm{rCBF}$ and neuronal activity constitute the basic principle for both PET and SPECT [53,54] and in absence of brain damage such as ischemia or trauma the auto-regulation and the CBF will be proportional to the Perfusion pressure [55]. Neuroimaging with rCBF-SPECT shows the functional state of the brain almost regardless of the structure of the brain. A reduction can be secondary to a low function due to hypome tabolism or secondary to neuronal loss with atrophy. Regardless of the cause of the reduction the low rCBF is secondary to a reduction of neuronal function with or without accompanying atrophy which should be kept in mind in the interpretation of rCBF-images.

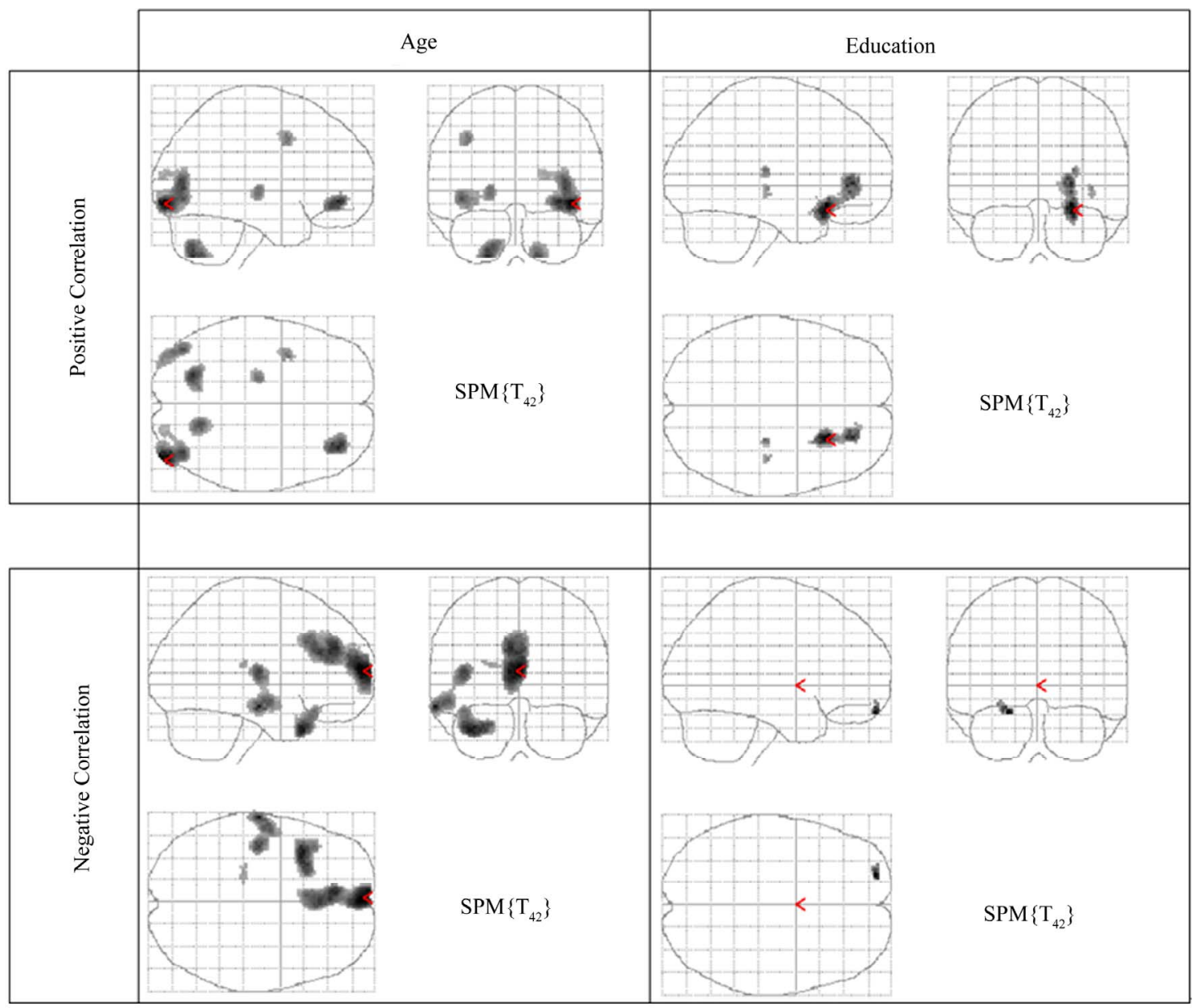

Figure 2. SPM MIP images showing positive and negative correlations $(p<0.001$ uncorrected), between rCBF and age (first column) and between rCBF and education (second column). 
Table 3. SPM data of rCBF differences in the correlation analysis of age and education length. The table shows size and Talairach coordinates of anatomical locations of significant clusters. The regions presented are significant at corrected $p$-value of $\boldsymbol{p}<0.05$ in clusters and/or $\boldsymbol{p}<0.05$ (FDR) in peaks.

\begin{tabular}{|c|c|c|c|c|c|c|c|c|}
\hline & $\begin{array}{l}\text { Size } \% \text { of } \\
\text { cluster* }\end{array}$ & $\begin{array}{c}\text { Size } \\
\mathrm{ml}\end{array}$ & $\begin{array}{l}\text { Corrected } p \\
\text { value, whole } \\
\text { cluster }\end{array}$ & $\begin{array}{l}\text { Number } \\
\text { of voxels } \\
\text { in cluster }\end{array}$ & $\begin{array}{l}\text { Fdr-corrected } p \\
\text { value of voxel }\end{array}$ & $\begin{array}{l}T \text { value of } \\
\text { voxel }\end{array}$ & $\begin{array}{l}\text { Uncorr. } p \\
\text { value of } \\
\text { voxel }\end{array}$ & $\begin{array}{c}\text { Talairach } \\
\text { coordinates } \\
\mathrm{x}, \mathrm{y}, \mathrm{z}\end{array}$ \\
\hline \multicolumn{9}{|l|}{ Anatomical region } \\
\hline \multicolumn{9}{|l|}{ Age pos. Correlation rCBF } \\
\hline \multicolumn{9}{|l|}{ Cluster 1} \\
\hline $\begin{array}{l}\text { R. Occipital Lobe, } \\
\text { Inferior Occipital Gyrus }\end{array}$ & 39 & 2.2 & 0.007 & 713 & 0.085 & 5.15 & 0.000 & $44,-88,-4$ \\
\hline $\begin{array}{l}\text { R. Occipital Lobe, } \\
\text { Middle Occipital Gyrus }\end{array}$ & 48 & 2.7 & & & 0.085 & 4.47 & 0.000 & $38,-74,6$ \\
\hline R. Sub-Gyral & 9 & 0.5 & & & & & & \\
\hline \multicolumn{9}{|l|}{ Age neg Correlation rCBF } \\
\hline \multicolumn{9}{|l|}{ Cluster 1} \\
\hline $\begin{array}{l}\text { L. Frontal Lobe, Midial } \\
\text { Frontal Gyrus }\end{array}$ & 38 & 5.0 & 0.000 & 1651 & 0.043 & 5.01 & 0.000 & $-2,62,4$ \\
\hline $\begin{array}{l}\text { R. Frontal Lobe, Midial } \\
\text { Frontal Gyrus }\end{array}$ & 4 & 0.5 & & & & & & \\
\hline $\begin{array}{l}\text { R. L. C. Anterior } \\
\text { Cingulate }\end{array}$ & 17 & 2.2 & & & & & & \\
\hline $\begin{array}{l}\text { R. L. C. Cingulate } \\
\text { Ggyrus }\end{array}$ & 13 & 1.7 & & & & & & \\
\hline Unidentified & 22 & 2.9 & & & & & & \\
\hline \multicolumn{9}{|l|}{ Cluster 2} \\
\hline $\begin{array}{l}\text { L. Temporal Lobe, } \\
\text { Superior Temporal } \\
\text { Gyrus }\end{array}$ & 64 & 2.4 & 0.031 & 475 & 0.043 & 4.69 & 0.000 & $-38,16,-29$ \\
\hline Unidentified & 32 & 1.2 & & & & & & \\
\hline \multicolumn{9}{|l|}{ Cluster 3} \\
\hline $\begin{array}{l}\text { L. Temporal Lobe, } \\
\text { Middle Temporal } \\
\text { Gyrus }\end{array}$ & 48 & 1.8 & 0.033 & 467 & 0.043 & 4.62 & 0.000 & $\begin{array}{l}-63,-16 \\
-13\end{array}$ \\
\hline L. Sub-lobar, Insula & 27 & 1.0 & & & 0.043 & 4.36 & 0.000 & $-42,-15,10$ \\
\hline $\begin{array}{l}\text { L. Temporal Lobe, } \\
\text { Middle Temporal } \\
\text { Gyrus }\end{array}$ & & 0.0 & & & 0.043 & 4.16 & 0.000 & $-57,-10-11$ \\
\hline $\begin{array}{l}\text { L. Temporal Lobe, } \\
\text { Superior Temporal } \\
\text { Gyrus }\end{array}$ & 14 & 0.5 & & & & & & \\
\hline \multicolumn{9}{|c|}{ Education pos correlation rCBF } \\
\hline \multicolumn{9}{|l|}{ Cluster 1} \\
\hline $\begin{array}{l}\text { R. Frontal Lobe Inferior } \\
\text { Frontal Gyrus }\end{array}$ & 39 & 1.3 & 0.053 & 401 & 0.492 & 4.20 & 0.000 & $26,21,-16$ \\
\hline $\begin{array}{l}\text { R. Frontal Lobe, } \\
\text { Sub-Gyral }\end{array}$ & 41 & 1.3 & & & 0.492 & 3.94 & 0.000 & $24,41,0$ \\
\hline $\begin{array}{l}\text { R. Frontal Lobe, Middle } \\
\text { Frontal Gyrus }\end{array}$ & 13 & 0.4 & & & & & & \\
\hline
\end{tabular}

*MSU (MNI Space utility) was used for an anatomical description of the significant clusters in terms of the Talairach daemon atlas "brain lobe" level. This is expressed as percent of cluster.

In the study by Barnden et al., no structural changes were observed in the magnetic resonance imaging (MRI) in contrast to the reduced uptake in the anterior cingulate in SPECT. The suggested partial volume effect (PVE) model of a sulcal widening at the junction of the interhemispheric fissure and cingulate sulcus in this study might explain their findings [20]. It is known that serial inter-individual quantitative MRI have shown global loss 
of volume in all cerebral regions during aging [56] and that especially frontal region are more sensitive to aging $[57,58]$. Therefore, it is most likely that the regions with uptake decrease in the present study mainly are an effect of global tissue loss with secondary widening of the interhemispheric and interlobar space and not by an actual rCBF decrease in preserved tissue. A model for this type of partial volume effect (PVE) at sulcal widening is provided in a work by Barnden 2005 [20].

The younger group did not show any regions withhigher rCBF, i.e. preservations in the group analysis although at the correlation analysis there was a significant negative correlation in the right occipital lobe. The fact that there was considerable low amount of regions with age related preservations compared to earlier SPECT studies $[8,16,17,20]$ might be an effect of the chosen SPM threshold in this study. It should be mentioned that there were bilateral parietal "preservations" in white matter at an uncorrected level of $p<0.001$.

At the spatial registration in SPM the uptake concentration is conserved [59] and in theory this will compensate for difference in size. This is convenient in matter of gender-based size differences but it is likely that this will mask global size differences based on neuronal loss or aging over the hemispheres. PET and especially SPECT images have a low spatial resolution with a lowgrade possibility to define the interhemispheric and interlobar spaces. The temporal lobe which has a high neuronanatomic variability $[10,60]$ does not provide delineating information for an optimal spatial normalization compared to the registration to the template over the hemispheres that probably is less sensitive to a low resolution. In case a structural modality, i.e. CT or MR is obtained this can be used to optimize the spatial normalization and also correct for PVE. Two recent papers studying age related changes in brain function at rest $[17,61]$ showed negative correlations between age and uptake in interlobar regions which is in line with the result in the present study. Both studies used a three-compartment segmentation (grey, white matter, and cerebrospinal fluid) method described by Matsuda [62] to compensate for PVE with difference level of success. In the study by Matsuda using PVE correction on rCBF-SPECT the negative age correlation remained in a greater extent than in a study by Yanase et al. using FDG-PET. Yanase suggest that this could be due to the differences in resolution and methodology. Further research is needed to evaluate this method although both Yanase and Matsuda recommend PVE correction for both modalities. This is however not easily done in the clinical setting. The present findings suggests that the age related reduction of rCBF in interlobar inter hemispheric space is mainly an effect of the normal reduction of brain tissue with in- creasing age, with a secondary widening of subarachnoid space. There is a PVE contributing to the detected rCBF loss and in order to further evaluate the PVE multimodal analysis with simultaneously performed SPECT/CT imaging has to be done.

In the clinical setting the interpretation of a detected rCBF reduction is always a loss of brain function and using simultaneous SPECT/CT images the correlation to a changed structure can be facilitated by fused images.

\subsection{Gender Related Difference}

Gender differences have been studied in several earlier studies and there are no consistent findings of differences in basal rCBF in healthy volunteers using PET or SPECT $[16,20,23,24]$.

In the present study the effect of gender on basal rCBF was not significant in either the group comparison or the correlation analysis. It should be mentioned, though, that there was a non-significant effect $(p<0.07$ FDR) with higher rCBF in women in a left temporal region which was also reported in a recent 99mTc-ECD SPECT study by Li et al. [63]. They used a SPM height threshold of P $<0.005$ uncorrected. Li suggested that this finding was due to a higher concentration of grey matter in women in this region since the finding disappeared after PVE correction [63].

\subsection{Education and Cognitive Reserve}

In our study the more educated elderly that were matched for age and gender to a group with fewer years of formal education had a significantly higher rCBF in the left temporal lobe. This has not been shown earlier in a healthy elderly population at rest. A similar effect of education length in the left temporal lobe has been seen in a recent study in an $\mathrm{AD}$ patient group [31]. In the present study the effect of education on left temporal rCBF was not seen in the correlation analysis. However, the correlation analysis of the whole sample showed a cluster with a positive correlation to rCBF in the right inferior frontal lobe. The cognitive reserve is in its nature an ability to perform on a higher level at a demand for an active brain process. Since our subjects were investigated at rest this should be considered. Nonetheless, our findings give further support for the theory of cognitive reserve [29] and the view that education length influences the basal rCBF. Results like those presented here are in line with some epidemiological and clinical data $[64,65]$ which support the theory of education as being protective to the development of $\mathrm{AD}$. In a twin study it was shown that longer education was more supportive against $\mathrm{AD}$ than genetic factors [27]. Studies showing patophysiologic or functional support for the theory are sparser and therefore we think that our result is of great interest in the ongoing 
discussion [28]. The present study is the second one pointing to a connection of educational length and the rCBF in the lateral temporal lobe at rest [31]. This region is affected in "semantic dementia" [33,66] and formal education is known to be associated with better memory performance, and particularly the semantic memory [67].

\subsection{MMSE}

In this study some of the included healthy subjects had a lower MMSE than in other comparable studies $[8,16]$. This was a reason for the group analysis of MMSE even though the range of MMSE was low. The included subjects with a lower MMSE were considered normal without dementia. As expected, there were no detected rCBF differences in the group analysis.

\subsection{Smoke and Ache}

The group analysis did not reveal any significant influence of ache or a history of smoking on the rCBF. The reported ache was considered as being of low-grade intensity since it did not affect the reported subjective good health. There was a non-significant ( $p<0.07$ FDR) finding of increased rCBF in bilateral parietal cortex and cingulum. The parietal region has been reported to be involved in pain processing in chronic neck pain patients [42].

Twelve of the sixteen subjects with a history of smoking had stopped smoking, while four were still smokers. This might have had an effect on the non-significant results.

\subsection{Normal rCBF in Relation to Dementia}

$\mathrm{AD}$ is the most common type of dementia and the most common diagnostic issue in rCBF-SPECT $[2-4,68,69]$. The localization of the major rCBF uptake findings differ between early versus late onset of the $\mathrm{AD}$. The typical finding in elderly $\mathrm{AD}$ patients tends to be characteristic involvement of the medial temporal lobes, (MTL) whereas early onset patients predominantly have a decreased rCBF in posterior cortical association regions [70]. This difference has also been shown in voxel based morphometric studies [71]. In the present study, there were no age related findings in regions typically affected in early $\mathrm{AD}$, i.e. the posterior temporal or the parietal lobe. However it should be considered that age as a confounder might disguise the $\mathrm{AD}$ changes in the anterior temporal lobe which might explain the discrepancy of reported changes in the anterior and medial temporal lobe and the findings at visual assessment. There seems to be several confounding factors involved in the sensitivity of detection of rCBF changes in the temporal lobe i.e. age, PVE and a high neuroanatomic variation. AD related changes in MTL is first detected by a decreased function (FDG-PET) followed by structural changes [72]. In clinical routine a reduced uptake in MTL in rCBF-SPECT should be related to age and if the finding is more pronounced than expected it should be considered regardless of cause, since AD progresses with both functional and structural changes. In relation to our finding of age related changes in healthy elderly it is shown that except for MTL the changes clearly differ from those in $\mathrm{AD}$ patients.

\subsection{Methodological Considerations}

One limitation of this study is that the subjects were examined only at a resting state. However, this is typically the case in clinical routine. The conclusions therefore concern only the baseline condition, although there is no reason to believe that the detected age related differences in perfusion is changed in an activated state.

SPM, which was used for spatial normalization, tries to preserve the concentration, when warping to a greater volume at the normalization step [59]. In this and some other studies of the age related differences in perfusion, the detected changes are in intracerebral, interlobar and interhemisheric regions $[17,61]$. These findings does not correspond to described age-related volume loss in structural imaging where the regions have been thoroughly delineated with ROI $[10,57,58,60]$. One explanation could be a methodological issue related to the spatial normalization method used in SPM in combination with the low resolution in SPECT. Although we used the established SPM procedure for spatial normalization, we cannot completely rule out the possibility that our findings were affected by the normalization step. This effect might be present in some voxel-based morphologic studies of the aging brain using MRI as well, such as the findings in a study by Good et al. that reported age-related accelerated volume loss in local areas bilaterally in the insula, superior parietal gyri, central sulci, and cingulate sulci, all in close relation to interlobar or interhemispheric space [14]. This may lead to a conclusion that findings close to interlobar and interhemispheric space using SPM may be disputable regardless of the modality used in the SPM analysis.

The sample size did not allow comparisons in subgroups of age. Since age is the major contributor to the variation of rCBF in elderly this might mask variations due to the other variables in this study. For instance women had a tendency of a higher rCBF in bilateral partial regions in the younger subgroup. Future rCBF studies of other variables than age would probably gain to a large extent if the variation of age is kept in a low range. This is especially important regarding possible education-related rCBF changes since the formal education length has changed over the years which could not be controlled for in this study. 


\subsection{Conclusions}

Age contributed to a vast extent to the variation in uptake measured with rCBF-SPECT. The significant age-related findings using SPM showed extensive regions mainly in intracerebral interlobar and interhemisperic spaces. The findings differ mostly from dementia-related findings and it should be stressed that $\mathrm{rCBF}$ changes in normal aging typically should not disturb the visual interpretation of $\mathrm{rCBF}$ in $\mathrm{AD}$. A reduction close to intracerebral interlobar space and especially MTL should be related to age and should be considered regardless of cause, since AD progresses with both functional and structural changes. Our results support that education influences the basal brain function and this could be interpreted as further support for the theory of cognitive reserve.

\section{Acknowledgements}

Financial support was provided by Lion's Cancer Research Foundation in Northern Sweden, the Swedish Knowledge Foundation, the Faculty of Medicine at Umeå University, the Swedish research council and Borger-skapet in Umeå research foundation. We thank the Betula project for providing control data.

\section{REFERENCES}

[1] A. Otte, "The Importance of the Control Group in Functional Brain Imaging," European Journal of Nuclear Medicine, Vol. 27, No. 9, 2000, pp. 1420. doi:10.1007/s002590000320

[2] N. J. Dougall, S. Bruggink and K. P. Ebmeier, "Systematic Review of the Diagnostic Accuracy of 99mTcHMPAO-SPECT in Dementia," American Journal of Geriatr Psychiatry, Vol. 12, No. 6, 2004, pp. 554-570.

[3] E. E. Camargo, "Brain SPECT in Neurology and Psychiatry,” Journal of Nuclear Medicine, Vol. 42, No. 4, 2001, pp. 611-623.

[4] G. Waldemar, P. Hogh and O. B. Paulson, "Functional Brain Imaging with Single-Photon Emission Computed Tomography in the Diagnosis of Alzheimer's Disease," International Psychogeriatrics, Vol. 9, Suppl. 1, 1997, pp. 223-227. doi:10.1017/S1041610297004924

[5] A. Lobo, L. J. Launer, L. Fratiglioni, K. Andersen, A. Di Carlo, M. M. Breteler et al., "Prevalence of Dementia and Major Subtypes in Europe: A Collaborative Study of Population-Based Cohorts. Neurologic Diseases in the Elderly Research Group,” Neurology, Vol. 54, No. 11, Suppl. 5, 2000, pp. S4-S9.

[6] S. G. Gauthier, “Alzheimer's Disease: The Benefits of Early Treatment,” European Journal of Neurology, Vol. 12, Suppl. 3, 2005, pp. 11-16. doi:10.1111/j.1468-1331.2005.01322.x

[7] K. J. Van Laere and R. A. Dierckx "Brain Perfusion Spect: Age and Sex-Related Effects Correlated with VoxelBased Morphometric Findings in Healthy Adults,” Radi- ology, Vol. 221, No. 3, 2001, pp. 810-817. doi:10.1148/radiol.2213010295

[8] M. Pagani, D. Salmaso, C. Jonsson, R. Hatherly, H. Jacobsson, S. A. Larsson, et al., "Regional Cerebral Blood Flow as Assessed by Principal Component Analysis and (99m)Tc-HMPAO SPET in Healthy Subjects at Rest: Normal Distribution and Effect of Age and Gender," European Journal of Nuclear Medicine and Molecular Imaging, Vol. 29, No. 1, 2002, pp. 67-75. doi:10.1007/s00259-001-0676-2

[9] J. S. Allen, J. Bruss and H. Damasio, "The Aging Brain: The Cognitive Reserve Hypothesis and Hominid Evolution,” American Journal of Human Biology, Vol. 17, No. 6, 2005, pp. 673-689. doi:10.1002/ajhb.20439

[10] J. S. Allen, J. Bruss, C. K. Brown and H. Damasio, "Normal Neuroanatomical Variation due to Age: The Major Lobes and a Parcellation of the Temporal Region," Neurobiol Aging, Vol. 26, No. 9, 2005, pp. 1245-60. doi:10.1016/j.neurobiolaging.2005.05.023

[11] K. Heininger, “A Unifying Hypothesis of Alzheimer’S Disease. IV. Causation and Sequence of Events," Reviews in the Neurosciences, Vol. 11, No. 0334-1763, 2000, pp. 213-328.

[12] S. Hagstadius and J. Risberg, "Regional Cerebral Blood Flow Characteristics and Variations with Age in Resting Normal Subjects," Brain and Cognition, Vol. 10, No. 1, 1989, pp. 28-43. doi:10.1016/0278-2626(89)90073-0

[13] D. O. Slosman, C. Chicherio, C. Ludwig, L. Genton, S. de Ribaupierre, D. Hans, et al., “(133)Xe SPECT Cerebral Blood Flow Study in a Healthy Population: Determination of T-scores,” Journal of Nuclear Medicine, Vol. 42, No. 6, 2001, pp. 864-870.

[14] C. D. Good, I. S. Johnsrude, J. Ashburner, R. N. Henson, K. J. Friston, R. S. Frackowiak, et al., "A Voxel- Based Morphometric Study of Ageing in 465 Normal Adult Human Brains,” NeuroImage, Vol. 14, No. 1, Part 1, 2001, pp. 21-36.

[15] A. R. Andersen, H. Friberg, K. B. Knudsen, D. I. Barry, O. B. Paulson, J. F. Schmidt, et al., "Extraction of [99mTc]-d, l-HM-PAO across the Blood-Brain Barrier," Journal of Cerebral Blood Flow \& Metabolism, Vol. 8, No. 6, 1988, pp. S44-S51. doi:10.1038/jcbfm.1988.32

[16] K. Van Laere, J. Versijpt, K. Audenaert, M. Koole, I. Goethals, E. Achten, et al., "99mTc-ECD Brain Perfusion Spet: Variability, Asymmetry and Effects of Age and Gender in Healthy Adults," European Journal of Nuclear Medicine, Vol. 28, No. 7, 2001, pp. 873-87. doi:10.1007/s002590100549

[17] H. Matsuda, T. Ohnishi, T. Asada, Z. J. Li, H. Kanetaka, E. Imabayashi, et al., "Correction for Partial-Volume Effects on Brain Perfusion SPECT in Healthy Men,” Journal of Nuclear Medicine, Vol. 44, No. 8, 2003, pp. 1243-1252.

[18] K. A. Ansari and J. Loch, "Decreased Myelin Basic Protein Content of the Aged Human Brain,” Neurology, Vol. 25, No. 11, 1975, pp. 1045-1050.

[19] W. Meier-Ruge, J. Ulrich, M. Bruhlmann and E. Meier, 
"Age-Related White Matter Atrophy in the Human Brain," Annals of the New York Academy of Sciences, Vol. 673, No. 26, 1992, pp. 260-269.

[20] L. R. Barnden, S. Behin-Ain, R. Kwiatek, R. Casse and L. Yelland, "Age Related Preservation and Loss in Optimized Brain SPECT,” Nuclear Medicine Communications, Vol. 26, No. 6, 2005, pp. 497-503. doi:10.1097/00006231-200506000-00004

[21] A. Herlitz, L. G. Nilsson and L. Backman, "Gender Differences in Episodic Memory,” Memory \& cognition, Vol. 25, No. 6, 1997, pp. 801-811. doi:10.3758/BF03211324

[22] S. F. Witelson, H. Beresh and D. L. Kigar "Intelligence and Brain Size in 100 Postmortem Brains: Sex, Lateralization and Age Factors,” Brain, Vol. 129, No. 2, 2006, pp. 386-398. doi:10.1093/brain/awh696

[23] K. Jones, K. A. Johnson, J. A. Becker, P. A. Spiers, M. S. Albert, B. L. Holman, et al., "Use of Singular Value Decomposition to Characterize Age and Gender Differences in SPECT Cerebral Perfusion,” Journal of Nuclear Medicine, Vol. 39, No. 6, 1998, pp. 965-973.

[24] T. Kawachi, K. Ishii, S. Sakamoto, M. Matsui, T. Mori, M. Sasaki, et al., "Gender Differences in Cerebral Glucose Metabolism: A PET Study,” Journal of the Neurological Sciences, Vol. 199, No. 1-2, 2002, pp. 79-83. doi:10.1016/S0022-510X(02)00112-0

[25] Y. Stern, G. E. Alexander, I. Prohovnik and R. Mayeux, "Inverse Relationship between Education and Parietotemporal Perfusion Deficit in Alzheimer's Disease," Journal of the Neurological Sciences, Vol. 32, No. 3, 1992, pp. 371-375.

[26] J. L. Cobb, P. A. Wolf, R. Au, R. White and R. B. D'Agostino, "The Effect of Education on the Incidence of Dementia and Alzheimer's Disease in the Framingham Study,” Neurology, Vol. 45, No. 9, 1995, pp. 1707-1712.

[27] M. Gatz, C. A. Reynolds, L. Fratiglioni, B. Johansson, J. A. Mortimer, S. Berg, et al., "Role of Genes and Environments for Explaining Alzheimer Disease," Archives of General Psychiatry, Vol. 63, No. 2, 2006, pp. 168-174. doi:10.1001/archpsyc.63.2.168

[28] J. Marx, "Neuroscience. Preventing Alzheimer's: A Lifelong Commitment?” Science, Vol. 309, No. 5736, 2005, pp. 864-866. doi:10.1126/science.309.5736.864

[29] Y. Stern, "What is Cognitive Reserve? Theory and Research Application of the Reserve Concept," Journal of the International Neuropsychological Society, Vol. 8, No. 3, 2002, pp. 448-460. doi:10.1017/S1355617702813248

[30] N. Scarmeas, E. Zarahn, K. E. Anderson, J. Hilton, J. Flynn, R. L. Van Heertum, et al., "Cognitive Reserve Modulates Functional Brain Responses during Memory Tasks: A PET Study in Healthy Young and Elderly Subjects,” NeuroImage, Vol. 19, No. 3, 2003, pp. 1215-1227. doi:10.1016/S1053-8119(03)00074-0

[31] N. T. Chiu, B. F. Lee, S. Hsiao and M. C. Pai, "Educational Level Influences Regional Cerebral Blood Flow inPatients with Alzheimer's Disease," Journal of Nuclear Medicine, Vol. 45, No. 11, 2004, pp. 1860-1863.

[32] E. L. Teng, K. Hasegawa, A. Homma, Y. Imai, E. Larson,
A. Graves, et al., "The Cognitive Abilities Screening Instrument (CASI): A Practical Test for Cross-Cultural Epidemiological Studies of Dementia,” International Psychogeriatric, Vol. 6, No. 1, 1994, pp. 45-58. doi:10.1017/S1041610294001602

[33] P. Garrard and J. R. Hodges "Semantic Dementia: Clinical, Radiological and Pathological Perspectives,” Journal of Neurology, Vol. 247, No. 6, 2000, pp. 409-422. doi:10.1007/s004150070169

[34] Y. C. Liao, R. S. Liu, E. L. Teng, Y. C. Lee, P. N. Wang, K. N. Lin, et al., "Cognitive Reserve: A SPECT Study of 132 Alzheimer's Disease Patients with an Education Range of 0-19 Years,” Dementia and Geriatric Cognitive Disorders, Vol. 20, No. 1, 2005, pp. 8-14. doi: $10.1159 / 000085068$

[35] P. H. Ghatan, M. Ingvar, L. Eriksson, S. Stone-Elander, M. Serrander, K. Ekberg, et al., "Cerebral Effects of Nicotine during Cognition in Smokers and Non-Smokers,” Psychopharmacology, Vol. 136, No. 2, 1998, pp. 179-189. doi:10.1007/s002130050554

[36] E. F. Domino, S. Minoshima, S. Guthrie, L. Ohl, L. Ni, R. A. Koeppe et al., "Nicotine Effects on Regional Cerebral Blood Flow in Awake, Resting Tobacco Smokers," Synapse, Vol. 38, No. 3, 2000, pp. 313-321.

doi:10.1002/1098-2396(20001201)38:3<313::AID-SYN1 $\underline{0>3.0 . C O ; 2-6}$

[37] J. E. Rose, F. M. Behm, E. C. Westman, R. J. Mathew, E. D. London, T. C. Hawk, et al. "PET Studies of the Influences of Nicotine on Neural Systems in Cigarette Smokers,” The American Journal of Psychiatry, Vol. 160, No. 2, 2003, pp. 323-333. doi:10.1176/appi.ajp.160.2.323

[38] Y. Yamamoto, Y. Nishiyama, T. Monden, K. Satoh and M. Ohkawa, "A Study of the Acute Effect of Smoking on Cerebral Blood Flow Using 99mTc-ECD SPET,” European Journal of Nuclear Medicine and Molecular Imaging, Vol. 30, No. 4, 2003, pp. 612-614. doi:10.1007/s00259-003-1119-z

[39] J. K. Zubieta, M. M. Heitzeg, Y. Xu, R. A. Koeppe, L. Ni, S. Guthrie, et al., "Regional Cerebral Blood Flow Responses to Smoking in Tobacco Smokers after overnight Abstinence,” The American Journal of Psychiatry, Vol. 162, No. 3, 2005, pp. 567-577. doi:10.1176/appi.ajp.162.3.567

[40] K. Yamashita, S. Kobayashi and S. Yamaguchi, “Cerebral Blood Flow and Cessation of Cigarette Smoking in Healthy Volunteers,” Internal Medicine, Vol. 39, No. 11, 2000, pp. 891-893. doi:10.2169/internalmedicine.39.891

[41] T. Rustoen, A. K. Wahl, B. R. Hanestad, A. Lerdal, S. Paul, C. Miaskowski, et al., "Age and the Experience Of Chronic Pain: Differences in Health and Quality of Life Among Younger, Middle-Aged, and Older Adults," The Clinical Journal of Pain, Vol. 21, No. 6, 2005, pp. 513-523.

[42] T. Sundstrom, M. Guez, C. Hildingsson, G. Toolanen, L. Nyberg, K. Riklund, et al., "Altered Cerebral Blood Flow in Chronic Neck Pain Patients but not in Whiplash Patients: A 99mTc-HMPAO rCBF Study,” European Spine Journal, Vol. 15, No. 8, 2006, pp. 1189-1195. 


\section{doi:10.1007/s00586-005-0040-5}

[43] L.-G. Nilsson, L. Bäckman, K. Erngrund, L. Nyberg, R. Adolfsson, G. Bucht, et al., "The Betula Prospective Cohort Study: Memory, Health, and Aging,” Aging, Neuropsychology, and Cognition, Vol. 4, No. 1, 1997, pp. 1-32. doi:10.1080/13825589708256633

[44] M. F. Folstein, S. E. Folstein and P. R. McHugh, "MiniMental State: A Practical Method for Grading the Cognitive State of Patients for the Clinician," Journal of Psychiatric Research, Vol. 12, No. 3, 1975, pp. 189-198. doi:10.1016/0022-3956(75)90026-6

[45] L. G. Nilsson, R. Adolfsson, L. Backman, C. M. de Frias, B. Molander, L. Nyberg, et al., "Betula: A Prospective Cohort Study on Memory, Health and Aging," Aging, Neuropsychology, and Cognition, Vol. 11, No. 2-3, 2004, pp. 134-148. doi:10.1080/13825580490511026

[46] S. R. Meikle, B. F. Hutton and D. L. Bailey, "A Transmission-Dependent Method for Scatter Correction in SPECT," Journal of Nuclear Medicine, Vol. 35, No. 2, 1994, pp. 360-367.

[47] K. J. Van Laere, J. Versijpt, M. Koole, S. Vandenberghe, P. Lahorte, I. Lemahieu, et al., "Experimental Performance Assessment of SPM for SPECT Neuroactivation Studies Using a Subresolution Sandwich Phantom Design,” NeuroImage, Vol. 16, No. 1, 2002, pp. 200-216. doi:10.1006/nimg.2001.1047

[48] H. M. Hudson and R. S. Larkin, "Accelerated Image Reconstruction Using Ordered Subsets of Projection Data," IEEE Transactions on Medical Imaging, Vol. 13, No. 4, 1994, pp. 601-609. doi:10.1109/42.363108

[49] K. Tatsch, S. Asenbaum, P. Bartenstein, A. Catafau, C. Halldin, L. S. Pilowsky, et al., "European Association of Nuclear Medicine Procedure Guidelines for Brain Perfusion SPET Using (99m)Tc-Labelled Radiopharmaceuticals," European Journal of Nuclear Medicine and Molecular Imaging, Vol. 29, No. 10, 2002, pp. BP36-42.

[50] C. R. Genovese, N. A. Lazar and T. Nichols, “Thresholding of Statistical Maps in Functional Neuroimaging Using the False Discovery Rate,” NeuroImage, Vol. 15, No. 4, 2002, pp. 870-878. doi:10.1006/nimg.2001.1037

[51] K. Inoue, H. Ito, R. Goto, M. Nakagawa, S. Kinomura, T. Sato, et al., "Apparent CBF Decrease with Normal Aging due to Partial Volume Effects: MR-Based Partial Volume Correction on CBF SPECT," Annals of Nuclear Medicine, Vol. 19, No. 4, 2005, pp. 283-290. doi:10.1007/BF02984620

[52] K. Takahashi, S. Yamaguchi, S. Kobayashi and Y. Yamamoto, "Effects of Aging on Regional Cerebral Blood Flow Assessed by Using Technetium Tc 99m Hexamethylpropyleneamine Oxime Single-Photon Emission Tomography with 3D Stereotactic Surface Projection Analysis,” American Journal of Neuroradiology, Vol. 26, No. 8, 2005, pp. 2005-2009.

[53] L. Sokoloff, "Relation between Physiological Function and Energy Metabolism in the Central Nervous System," Journal of Neurochemistry, Vol. 29, No. 1, 1977, pp. 13-26. doi:10.1111/j.1471-4159.1977.tb03919.x
[54] P. T. Fox and M. E. Raichle, "Focal Physiological Uncoupling of Cerebral Blood Flow and Oxidative Metabolism during Somatosensory Stimulation in Human Subjects," Proceedings of the National Academy of Sciences of the USA, Vol. 83, No. 4, 1986, pp. 1140-1144. doi:10.1073/pnas.83.4.1140

[55] S. Strandgaard and O. B. Paulson, "Cerebral Autoregulation,” Stroke, Vol. 15, No. 3, 1984, pp. 413-416.

[56] R. S. Liu, L. Lemieux, G. S. Bell, S. M. Sisodiya, S. D. Shorvon, J. W. Sander, et al., "A Longitudinal Study of Brain Morphometrics Using Quantitative Magnetic Resonance Imaging and Difference Image Analysis,” NeuroImage, Vol. 20, No. 1, 2003, pp. 22-33. doi:10.1016/S1053-8119(03)00219-2

[57] N. Raz, F. M. Gunning, D. Head, J. H. Dupuis, J. McQuain, S. D. Briggs, et al., "Selective Aging of the Human Cerebral Cortex Observed in Vivo: Differential Vulnera- bility of the Prefrontal Gray Matter," Cerebral Cortex, Vol. 7, No. 3, 1997, pp. 268-282. doi:10.1093/cercor/7.3.268

[58] N. Raz, U. Lindenberger, K. M. Rodrigue, K. M. Kennedy, D. Head, A. Williamson, et al., "Regional Brain Changes in Aging Healthy Adults: General Trends, Individual Differences and Modifiers," Cerebral Cortex, Vol. 15, No. 11, 2005, pp. 1676-1689. doi:10.1093/cercor/bhi044

[59] J. Ashburner, “Computational Neuroanatomy,” Ph.D. Thesis, University College London, London, 2000.

[60] J. S. Allen, H. Damasio and T. J. Grabowski, "Normal Neuroanatomical Variation in the Human Brain: An MRIVolumetric Study," American Journal of Physical Anthropology, Vol. 118, No. 4, 2002, pp. 341-358. doi:10.1002/ajpa.10092

[61] D. Yanase, I. Matsunari, K. Yajima, W. Chen, A. Fujikawa, S. Nishimura, et al., "Brain FDG PET Study of Normal Aging in Japanese: Effect of Atrophy Correction," European Journal of Nuclear Medicine and Molecular Imaging, Vol. 32, No. 7, 2005, pp. 794-805. doi:10.1007/s00259-005-1767-2

[62] H. Matsuda, H. Kanetaka, T. Ohnishi, T. Asada, E. Imabayashi, S. Nakano, et al., "Brain SPET Abnormalities in Alzheimer's Disease before and after Atrophy Correction," European Journal of Nuclear Medicine and Molecular Imaging, Vol. 29, No. 11, 2002, pp. 1502-1505. doi:10.1007/s00259-002-0930-2

[63] Z. J. Li, H. Matsuda, T. Asada, T. Ohnishi, H. Kanetaka, E. Imabayashi, et al., "Gender Difference in Brain Perfusion 99mTc-ECD SPECT in Aged Healthy Volun- teers after Correction for Partial Volume Effects," Nu- clear Medicine Communications, Vol. 25, No. 10, 2004, pp. 999-1005. doi:10.1097/00006231-200410000-00003

[64] N. Scarmeas, S. M. Albert, J. J. Manly and Y. Stern, "Education and Rates of Cognitive Decline in Incident Alzheimer's Disease," Journal of Neurology, Neurosurgery \& Psychiatry, Vol. 77, No. 3, 2006, pp. 308-316. doi:10.1136/jnnp.2005.072306

[65] A. Karp, I. Kareholt, C. Qiu, T. Bellander, B. Winblad, L. 
Fratiglioni, et al., "Relation of Education and Occupation-Based Socioeconomic Status to Incident Alzheimer's Disease," American Journal of Epidemiology, Vol. 159, No. 2, 2004, pp. 175-183. doi:10.1093/aje/kwh018

[66] P. J. Nestor, T. D. Fryer and J. R. Hodges, "Declarative Memory Impairments in Alzheimer's Disease and Semantic Dementia," NeuroImage, Vol. 30, No. 3, 2005, pp. 1010-1020.

[67] M. Lovden, M. Ronnlund, A. Wahlin, L. Backman, L. Nyberg, L. G. Nilsson, et al., "The Extent of Stability and Change in Episodic and Semantic Memory in Old Age: Demographic Predictors of Level and Change," The Journals of Gerontology, Series B: Psychological Sciences and Social Sciences, Vol. 59, No. 3, 2004, pp. P130-P134.

[68] W. J. Jagust, "Functional Imaging Patterns in Alzheimer's Disease. Relationships to Neurobiology," Annals of the New York Academy of Sciences, Vol. 777, No. 1, 1996, pp. 30-36. doi:10.1111/j.1749-6632.1996.tb34398.x

[69] P. R. Talbot, J. J. Lloyd, J. S. Snowden, D. Neary and H. J. Testa, "A Clinical Role for 99mTc-HMPAO SPECT in the Investigation of Dementia?” Journal of Neurology, Neurosurgery \& Psychiatry, Vol. 64, No. 3, 1998, pp. 306-313. doi:10.1136/jnnp.64.3.306

[70] P. M. Kemp, C. Holmes, S. M. Hoffmann, L. Bolt, R. Holmes, J. Rowden, et al., “Alzheimer's Disease: Differences in Technetium-99m HMPAO SPECT Scan Findings between Early Onset and Late Onset Dementia," Journal of Neurology, Neurosurgery \& Psychiatry, Vol. 74, No. 6, 2003, pp. 715-719. doi:10.1136/jnnp.74.6.715

[71] K. Ishii, T. Kawachi, H. Sasaki, A. K. Kono, T. Fukuda, Y. Kojima, et al., "Voxel-Based Morphometric Comparison between Early- and Late-Onset Mild Alzheimer's Disease and Assessment of Diagnostic Performance of $\mathrm{z}$ Score Images,” American Journal of Neuroradiology, Vol. 26, No. 2, 2005, pp. 333-340.

[72] L. Mosconi, S. De Santi, Y. Li, J. Li, J. Zhan, W. H. Tsui, et al., "Visual Rating of Medial Temporal Lobe Metabolism in Mild Cognitive Impairment and Alzheimer's Disease Using FDG-PET," European Journal of Nuclear Medicine and Molecular Imaging, Vol. 33, No. 2, 2006, pp. 210-221. doi:10.1007/s00259-005-1956-Z 